\title{
Article \\ Measurements of the Electrical Conductivity of Monolayer Graphene Flakes Using Conductive Atomic Force Microscopy
}

\author{
Soomook Lim ${ }^{1}$, Hyunsoo Park ${ }^{1}$, Go Yamamoto ${ }^{2}\left(\mathbb{D}\right.$, Changgu Lee $^{1,3}$ and Ji Won Suk $1,3,4, *$ (D) \\ 1 School of Mechanical Engineering, Sungkyunkwan University, Suwon 16419, Gyeonggi-do, Korea; \\ growing18@naver.com (S.L.); park102811@gmail.com (H.P.); peterlee@skku.edu (C.L.) \\ 2 Department of Aerospace Engineering, Tohoku University, 6-6-01 Aramaki-Aza-Aoba, Aoba-ku, \\ Sendai 980-8579, Japan; gyamamoto@tohoku.ac.jp \\ 3 SKKU Advanced Institute of Nanotechnology (SAINT), Sungkyunkwan University, \\ Suwon 16419, Gyeonggi-do, Korea \\ 4 Department of Smart Fab. Technology, Sungkyunkwan University, Suwon 16419, Gyeonggi-do, Korea \\ * Correspondence: jwsuk@skku.edu; Tel.: +82-31-290-7469
}

Citation: Lim, S.; Park, H.;

Yamamoto, G.; Lee, C.; Suk, J.W.

Measurements of the Electrical

Conductivity of Monolayer Graphene Flakes Using Conductive Atomic

Force Microscopy. Nanomaterials 2021,

11, 2575. https://doi.org/10.3390/

nano11102575

Academic Editor: Ana M. Benito

Received: 10 August 2021

Accepted: 23 September 2021

Published: 30 September 2021

Publisher's Note: MDPI stays neutral with regard to jurisdictional claims in published maps and institutional affiliations.

Copyright: (c) 2021 by the authors. Licensee MDPI, Basel, Switzerland. This article is an open access article distributed under the terms and conditions of the Creative Commons Attribution (CC BY) license (https:// creativecommons.org/licenses/by/ $4.0 /)$.

\begin{abstract}
The intrinsic electrical conductivity of graphene is one of the key factors affecting the electrical conductance of its assemblies, such as papers, films, powders, and composites. Here, the local electrical conductivity of the individual graphene flakes was investigated using conductive atomic force microscopy (C-AFM). An isolated graphene flake connected to a pre-fabricated electrode was scanned using an electrically biased tip, which generated a current map over the flake area. The current change as a function of the distance between the tip and the electrode was analyzed analytically to estimate the contact resistance as well as the local conductivity of the flake. This method was applied to characterize graphene materials obtained using two representative large-scale synthesis methods. Monolayer graphene flakes synthesized by chemical vapor deposition on copper exhibited an electrical conductivity of $1.46 \pm 0.82 \times 10^{6} \mathrm{~S} / \mathrm{m}$. Reduced graphene oxide (rGO) flakes obtained by thermal annealing of graphene oxide at 300 and $600{ }^{\circ} \mathrm{C}$ exhibited electrical conductivities of $2.3 \pm 1.0$ and $14.6 \pm 5.5 \mathrm{~S} / \mathrm{m}$, respectively, showing the effect of thermal reduction on the electrical conductivity of rGO flakes. This study demonstrates an alternative method to characterizing the intrinsic electrical conductivity of graphene-based materials, which affords a clear understanding of the local properties of individual graphene flakes.
\end{abstract}

Keywords: graphene; reduced graphene oxide; flakes; conductive atomic force microscopy; electrical conductivity

\section{Introduction}

Since the intriguing electronic properties of graphene have been experimentally observed in mechanically cleaved graphene [1-3], it has gained significant attention in various applications owing to its remarkable electrical, mechanical, thermal, and optical properties [4-7]. Two dominant methods for obtaining monolayer graphene in large quantities or large areas have been developed to overcome the limitations of mechanical cleavage from graphite. Chemical vapor deposition (CVD) on metals produces high-quality monolayer graphene with a nearly unlimited length [8]. In contrast, the exfoliation of oxidized graphite into a monolayer and the subsequent reduction produce large quantities of graphene flakes [9].

Electrical conductivity is one of the most important properties of synthesized graphene. However, the intrinsic electrical conductivity of graphene is significantly affected by its atomic and chemical structures. For example, the presence of grain boundaries in polycrystalline CVD-grown graphene deteriorates its electrical conductivity owing to the scattering at the grain boundary interfaces [10]. Graphene oxide (GO) obtained by exfoliation of 
graphite oxide contains oxygen functional groups such as hydroxyl, carboxyl, and epoxide [11]. Therefore, GO is electrically insulating and requires an additional chemical or thermal reduction for applications in electrically conductive devices or materials. However, the removal of oxygen functional groups in $\mathrm{GO}$ is dependent on the reduction conditions, which significantly affects the electrical conductivity of reduced graphene oxide (rGO) [12]. In addition, even after the removal of the oxygen functional groups, atomic defects exist in rGO; these originate from the strong oxidation-reduction process [13]. In this respect, measurements of the intrinsic electrical properties of monolayer graphene are highly correlated with its atomic and chemical structures and are of considerable importance in gaining an understanding of synthesized graphene.

The electrical properties of monolayer graphene have been investigated using several methods. To characterize individual graphene flakes, micro-sized metal electrodes were patterned on a graphene flake using photolithography techniques. Although this method has been extensively used to study the electrical properties of graphene flakes, such as mechanically exfoliated graphene and individual GO flakes [1,12], it requires complex microfabrication techniques, including positioning graphene flakes, coating a photoresist layer, depositing a metal layer, and removing the photoresist, which hinder the rapid characterization of mass-produced graphene materials. Macroscopic samples obtained by assembling individual graphene flakes have been widely used to characterize the electrical properties of mass-produced graphene-based materials, including papers fabricated by the layer-by-layer assembly of GO flakes and subsequent reduction [14], compressed graphene powders [15], and composites comprising graphene and polymer matrix [16]. However, the macroscopic assembly of graphene materials cannot fully reflect the electrical properties of individual graphene flakes because other factors, such as the morphology of graphene flakes, interactions between graphene and the polymer, and the non-uniform dispersion of graphene, may affect the electrical properties of the macroscopic assembly. Recently, conductive atomic force microscopy (C-AFM) has been utilized to study the local electrical properties of graphene sheets [17-19]. However, there is still a demand for characterizing individual graphene flakes synthesized using scalable production methods.

In this study, we employed C-AFM to directly measure the electrical conductivity of individual graphene flakes prepared by two prominent scalable synthesis methods: CVD on copper and the thermal reduction of GO. Without using any additional materials for electrical measurements, a graphene flake connected to a pre-fabricated electrode was scanned using an AFM tip, which generated an in-plane current distribution. The current change was analyzed as a function of the distance from the electrode to extract the electrical conductivity of the individual graphene flakes. This method was applied to CVD-grown monolayer graphene flakes. Furthermore, individual rGO flakes were characterized as a function of the degree of thermal reduction.

\section{Materials and Methods}

\subsection{Preparation of Monolayer Graphene Flakes}

High-quality sub-monolayer graphene was synthesized on copper foil using lowpressure chemical vapor deposition (LPCVD) [8]. Copper foil (46986, Alfa Aesar, Haverhill, MA, USA) was immersed in acetic acid to remove the native copper oxide. The cleaned copper foil was placed in a tube furnace and annealed with hydrogen at $950{ }^{\circ} \mathrm{C}$ for $60 \mathrm{~min}$ prior to graphene growth. A mixture of methane and hydrogen was introduced to synthesize monolayer graphene on copper at $950{ }^{\circ} \mathrm{C}$. The growth time was adjusted to synthesize flower-shaped sub-monolayer graphene; the injection of methane was stopped before the individual graphene flakes merged to form a continuous layer.

The polymer-assisted wet transfer method was used to place CVD-grown monolayer graphene flakes on $\mathrm{SiO}_{2} / \mathrm{Si}[20,21]$. Poly(methyl methacrylate) (PMMA, Mw 996,000, Sigma-Aldrich, St. Louis, MO, USA) dissolved in chlorobenzene $(15 \mathrm{mg} / \mathrm{mL}$, SigmaAldrich, St. Louis, MO, USA) was spin-coated onto the graphene/copper foil. After drying in air, the copper foil was etched by placing the sample on the surface of an ammonium 
persulfate solution (0.1 M, Sigma-Aldrich, St. Louis, MO, USA). The PMMA/graphene film was moved to the surface of water several times to rinse off the residue of the etchant. The PMMA/graphene film was moved to a $\mathrm{SiO}_{2} / \mathrm{Si}$ substrate, and the PMMA was removed with acetone after drying completely.

To obtain individual rGO flakes, GO flakes dispersed in water (GO-A-400, Grapheneall, Siheung, Korea) were spread on a $\mathrm{SiO}_{2} / \mathrm{Si}$ substrate after centrifuging the solution at $3000 \mathrm{rpm}$ for $1 \mathrm{~h}$ and taking out the upper part of the solution. The GO flakes on $\mathrm{SiO}_{2}$ were converted to rGO flakes via thermal annealing with hydrogen $(5 \mathrm{sccm})$ and argon $(80 \mathrm{sccm})$ at atmospheric pressure for $1 \mathrm{~h}$. The samples were annealed at two different temperatures $\left(300\right.$ and $600{ }^{\circ} \mathrm{C}$ ) to change the reduction degree of the rGO flakes.

\subsection{Electrical Measurements Using C-AFM}

The electrical conductivities of the individual graphene flakes were characterized using C-AFM (E-sweep/Nanonavi station, Hitachi High-Tech Science Co., Tokyo, Japan). Metal electrodes $(\mathrm{Cr}(10 \mathrm{~nm}) / \mathrm{Au}(40 \mathrm{~nm}))$ were pre-fabricated on a $\mathrm{SiO}_{2} / \mathrm{Si}$ substrate (285 $\mathrm{nm}$ thick $\mathrm{SiO}_{2}$ and highly doped $\mathrm{Si}$ with a resistivity of $0.001-0.005 \Omega \cdot \mathrm{cm}$ ) using photolithography and metal deposition. After placing graphene flakes on the $\mathrm{SiO}_{2} / \mathrm{Si}$ substrate, the electrical conductance of a graphene flake connected to the electrode was measured using contact-mode C-AFM with a metal-coated tip (Si tip coated with Pt/Ir, SCM-PIT-V2, Bruker, Billerica, MA, USA) with an elastic constant of $3 \mathrm{~N} / \mathrm{m}$ and a resonance frequency of $75 \mathrm{kHz}$. The electrical current was measured as a function of the applied bias voltage. All the measurements were performed at room temperature in the air.

Figure 1a shows the electrical measurements of the graphene flakes using C-AFM. A graphene flake placed on a $\mathrm{SiO}_{2} / \mathrm{Si}$ substrate was in contact with a pre-fabricated electrode. An AFM tip coated with metal made physical contact with a graphene flake, creating a closed circuit. A constant voltage was applied to the electrode, and the current flowing through the graphene flake was measured between the AFM tip and the electrode. By scanning the tip over the graphene flake, the resistance profile converted from the measured current was obtained as a function of the distance $(\mathrm{L})$ between the tip and the electrode. The total resistance $\left(R_{\text {total }}\right)$ is the sum of the resistance of graphene $\left(R_{\mathrm{g}}\right)$ and the contact resistance $\left(R_{c}\right)$. Because the C-AFM-based electrical measurement consists of graphene, an AFM tip, and an electrode, the total contact resistance $\left(R_{c}\right)$ includes the contact resistances of the tip $\left(R_{c, t}\right)$ and the electrode $\left(R_{c, e}\right)$ with graphene (Figure $\left.1 a\right)$.

$$
R_{\text {total }}=R_{g}+R_{c, e}+R_{c, t}=R_{g}+R_{c}
$$

(a)

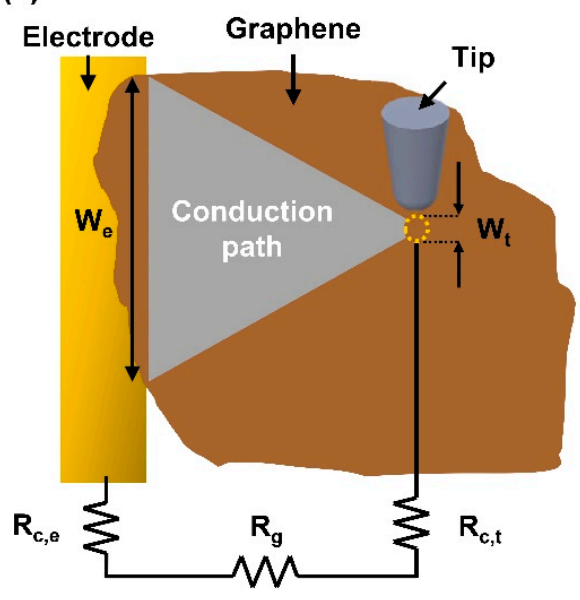

(b)

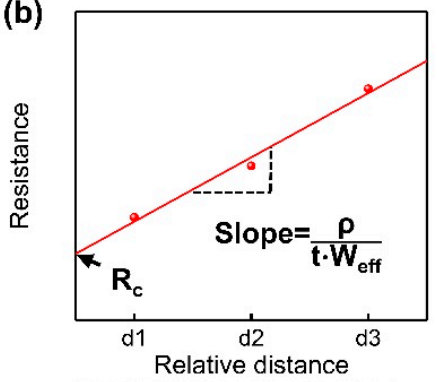

(c)

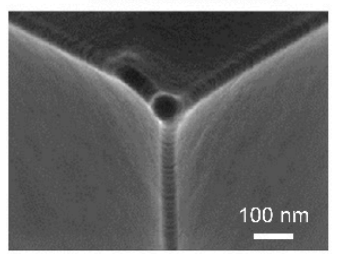

Figure 1. (a) Schematic illustration of the electrical measurements of graphene flakes using C-AFM. (b) Schematic illustration of the resistance profile as a function of the distance between the tip and the electrode. (c) SEM image of the AFM tip. 
By considering the triangular region formed by the tip and the electrode side as the electrical conduction path, it is possible to estimate the resistance of graphene $\left(R_{g}\right)$ using the following equation $[19,22]$ :

$$
\begin{gathered}
R_{g}=\rho \frac{L}{t W_{e f f}}=\rho \frac{L}{t} \frac{\ln \left(\frac{W_{e}}{W_{t}}\right)}{\left(W_{e}-W_{t}\right)} \\
W_{e f f}=\frac{W_{e}-W_{t}}{\ln \left(\frac{W_{e}}{W_{t}}\right)}
\end{gathered}
$$

where $\rho$ is the resistivity of graphene, $t$ is the thickness of graphene, $W_{\mathrm{e}}$ is the connected length between the graphene and the electrode, $\mathrm{W}_{\mathrm{t}}$ is the diameter of the contact area under the tip, and $\mathrm{W}_{\text {eff }}$ is the effective conduction width of the graphene flakes. After obtaining the resistance profile as a function of the distance of the tip from the electrode, the contact resistance is estimated from the intercept at the $y$-axis (Figure 1b), which is similar to the transmission line measurement (TLM) method [23]. The slope of the linearly fitted curve provides the resistivity (the reciprocal of the conductivity) of the graphene flakes using the following equation (Figure 1b):

$$
\text { slope }=\frac{\rho}{t W_{e f f}}
$$

Because it is difficult to measure the actual contact area of the AFM tip, the Hertz contact model was employed to estimate the diameter of the tip contact area $\left(W_{t}\right)$ [19]. Based on the Hertz contact model, the applied force is related to the radius of the AFM tip $\left(\mathrm{R}_{\text {tip }}\right)$, elastic indentation depth $(\delta)$, and reduced Young's modulus $(\mathrm{K})$ as follows [24]:

$$
F=K R_{\text {tip }}^{1 / 2} \delta^{3 / 2}
$$

The reduced Young's modulus $(\mathrm{K})$ is defined as follows:

$$
\frac{1}{K}=\frac{3}{4}\left(\frac{1-v_{s}^{2}}{E_{s}}+\frac{1-v_{t}^{2}}{E_{t}}\right)
$$

where $E_{t}$ and $E_{s}$ are the elastic moduli of the tip and the sample, respectively. $v_{t}$ and $v_{s}$ are the Poisson's ratios of the tip and the sample, respectively. The radius of the tip was measured to be $33 \mathrm{~nm}$ from the SEM image, as shown in the inset of Figure 1c.

However, the Hertz model only considers the contact pressure inside the contact area in the absence of adhesive interactions [25]. Thus, the Derjaguin-Múller-Toporov (DMT) contact model was used to estimate the contact area because a previous study had shown that adhesive interactions between a sharp indentation tip and monolayer graphene were in the DMT regime [26,27]. Based on the DMT contact model, the adhesion force between the tip and the sample $\left(\mathrm{F}_{\mathrm{ad}}\right)$ is involved in the estimation of the contact radius (a) as follows [24]:

$$
a=\left[\frac{R_{t i p}}{K}\left(F+F_{a d}\right)\right]^{1 / 3}
$$

The adhesion force $\left(\mathrm{F}_{\mathrm{ad}}\right)$ was estimated according to the force-distance curve from the AFM indentation $[24,28]$. The elastic moduli of CVD-grown graphene and rGO flakes were assumed to be 1 and $0.25 \mathrm{TPa}$, respectively, according to previous reports [5,29].

\subsection{Characterization of Graphene Materials}

The morphology of the monolayer graphene flakes was characterized using scanning electron microscopy (SEM, JSM-7600, Jeol, Tokyo, Japan). The changes in the chemical structures of GO and rGO were investigated using X-ray photoelectron spectroscopy (XPS, ESCALAB-250, Thermo-Scientific, Waltham, MA, USA) with monochromated Al K $\alpha$ radiation. The $\mathrm{C} 1$ s core-level spectra were deconvoluted with Gaussian-Lorentzian functions 
after a background signal correction using the Shirley profile [30]. The $\mathrm{sp}^{2}$-hybridized carbon $(C=C)$ was modeled using the asymmetric Doniach-Sunjic peak shape [31,32]. In addition, Raman spectroscopy (ALPHA300M with a $532 \mathrm{~nm}$ excitation laser, WiTec, Ulm, Germany) was used to characterize the graphitic structures of CVD-grown graphene, GO, and rGO.

\section{Results and Discussion}

\subsection{Electrical Conductivity of CVD-Grown Monolayer Graphene Flakes}

The intrinsic electrical conductivity of the CVD-grown graphene was characterized using the C-AFM measurement method. To isolate a graphene flake for electrical measurements, the growth of monolayer graphene was stopped by turning off the methane flow before forming continuous graphene on a copper foil. Therefore, many graphene flakes were formed on the surface of the copper foil (inset of Figure 2a). They were transferred onto $\mathrm{SiO}_{2} / \mathrm{Si}$ for electrical measurements, as shown in Figure 2a. Because the growth of graphene was stopped prior to the formation of the continuous film, the individual graphene flakes did not include grain boundaries [33], implying that the electrical measurements on these graphene flakes could provide the electrical conductivity of single-crystal graphene.
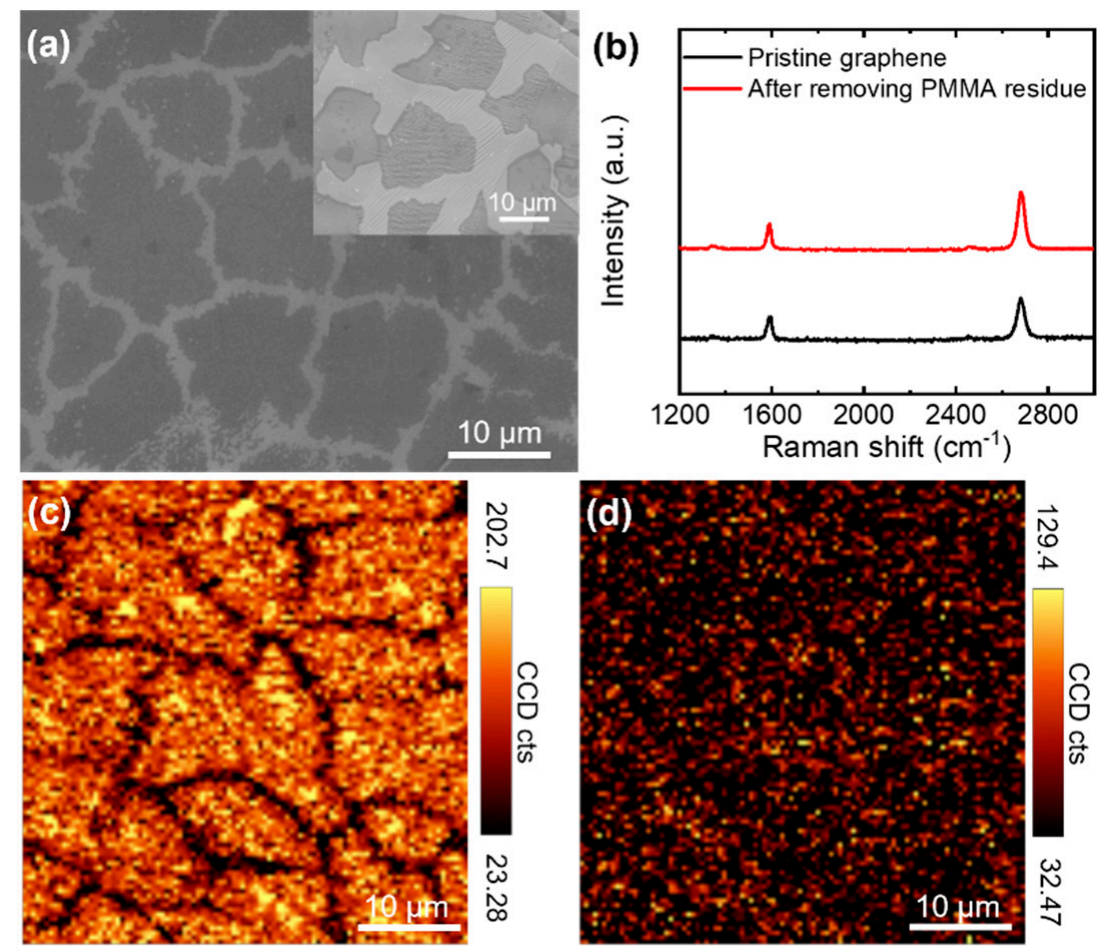

Figure 2. (a) SEM image of CVD-grown monolayer graphene flakes transferred onto $\mathrm{SiO}_{2}$. $\mathrm{The}$ inset shows the SEM image of monolayer graphene grown on the surface of copper foil. (b) Raman spectra of CVD-grown monolayer graphene placed on $\mathrm{SiO}_{2}$ before and after the removal of the polymer residue. (c,d) Raman maps for the integrated intensity of (c) the $G\left(1542-1642 \mathrm{~cm}^{-1}\right)$ and (d) D bands $\left(1314-1414 \mathrm{~cm}^{-1}\right)$.

Raman spectra obtained from the graphene flakes show the characteristic features of high-quality monolayer graphene (Figure $2 b$ ); the peak intensity of the $2 \mathrm{D}$ band at $\sim 2680 \mathrm{~cm}^{-1}$ was higher than that of the $\mathrm{G}$ band at $\sim 1580 \mathrm{~cm}^{-1}$, and there was a minimal $\mathrm{D}$ band at $\sim 1350 \mathrm{~cm}^{-1}$ [8]. Moreover, the Raman map for the integrated intensity of the G band (1542-1642 $\mathrm{cm}^{-1}$ ) confirms the existence of monolayer graphene flakes over a large area (Figure 2c), while the Raman map for the D band $\left(1314-1414 \mathrm{~cm}^{-1}\right)$ indicates a negligible defect distribution in the flakes (Figure 2d). 
Because CVD-grown graphene flakes were covered with a thin polymer layer during the wet transfer process, polymer residues on top of graphene could not be avoided even after removing the polymer with acetone [34]. Because the residual polymer layer might hinder the observation of the intrinsic electrical conductivity of graphene, it was removed through physical sweeping with an AFM tip in a contact-mode scan [35,36]. After scanning, the polymer residue on graphene was removed and stacked on the right side of the scanned area, as shown in Figure 3a. Due to the removal of the rough polymer residue, the root-mean-square (RMS) roughness decreased from $1.45 \mathrm{~nm}$ to $1.07 \mathrm{~nm}$, which was in good agreement with a previous study [35]. Therefore, the local current increased after the removal of the polymer residue (Figure $3 b$ ). In addition, contact-mode scanning was performed at a slow rate to avoid defect generation. The unchanged D band in the Raman spectra after scanning indicated that the polymer removal process did not affect the quality of graphene (Figure $2 b, d)$.
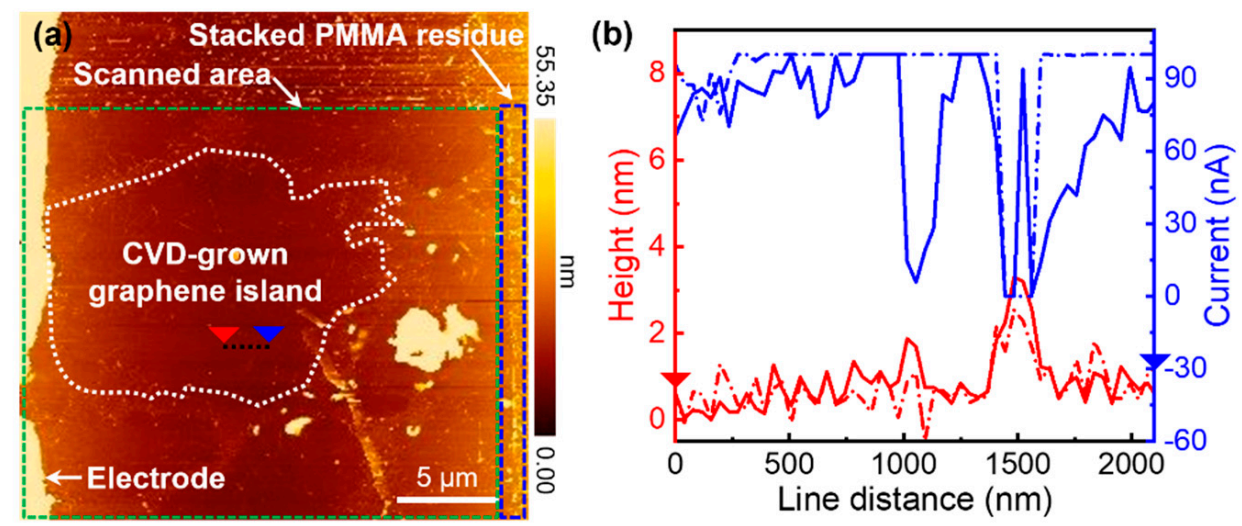

Figure 3. (a) AFM topography image of a CVD-grown monolayer graphene flake on $\mathrm{SiO}_{2}$ after the removal of the polymer residue. (b) The line profile of the current and morphology of the flake along the dashed line marked in (a).

Figure $4 \mathrm{a}, \mathrm{b}$ shows the AFM topography and current map of a CVD-grown graphene flake, respectively. The length of graphene connected to the electrode $\left(W_{\mathrm{e}}\right)$ was $4.33 \mu \mathrm{m}$. The force-distance curve exhibited a pull-off force of $57.6 \pm 13 \mathrm{nN}$ when $3 \mathrm{nN}$ was applied to the cantilever (Figure $4 \mathrm{c}$ ). Therefore, the contact area estimated using the DMT contact model was $13.487 \mathrm{~nm}^{2}\left(\mathrm{~W}_{\mathrm{t}}=4.144 \mathrm{~nm}\right)$. Figure $4 \mathrm{~d}$ shows the measured resistance as a function of the distance from the AFM tip to the electrode. By fitting the resistance curve with the exception of the low conductive spots, the electrical conductivity of CVD-grown monolayer graphene flakes was approximately estimated to be $1.46 \pm 0.82 \times 10^{6} \mathrm{~S} / \mathrm{m}$. This is close to the sheet resistances of CVD-grown monolayer graphene measured by the van der Pauw method in previous studies [21,37].

\subsection{Electrical Conductivity of Thermally Reduced Graphene Oxide Flakes}

The electrical conductivity of rGO flakes obtained by thermally reducing the GO flakes placed on $\mathrm{SiO}_{2} / \mathrm{Si}$ was characterized by C-AFM measurements. GO flakes were thermally annealed at two different temperatures $\left(300\right.$ and $\left.600{ }^{\circ} \mathrm{C}\right)$ to investigate the effect of the reducing temperature on the electrical conductivity of the rGO flakes. 

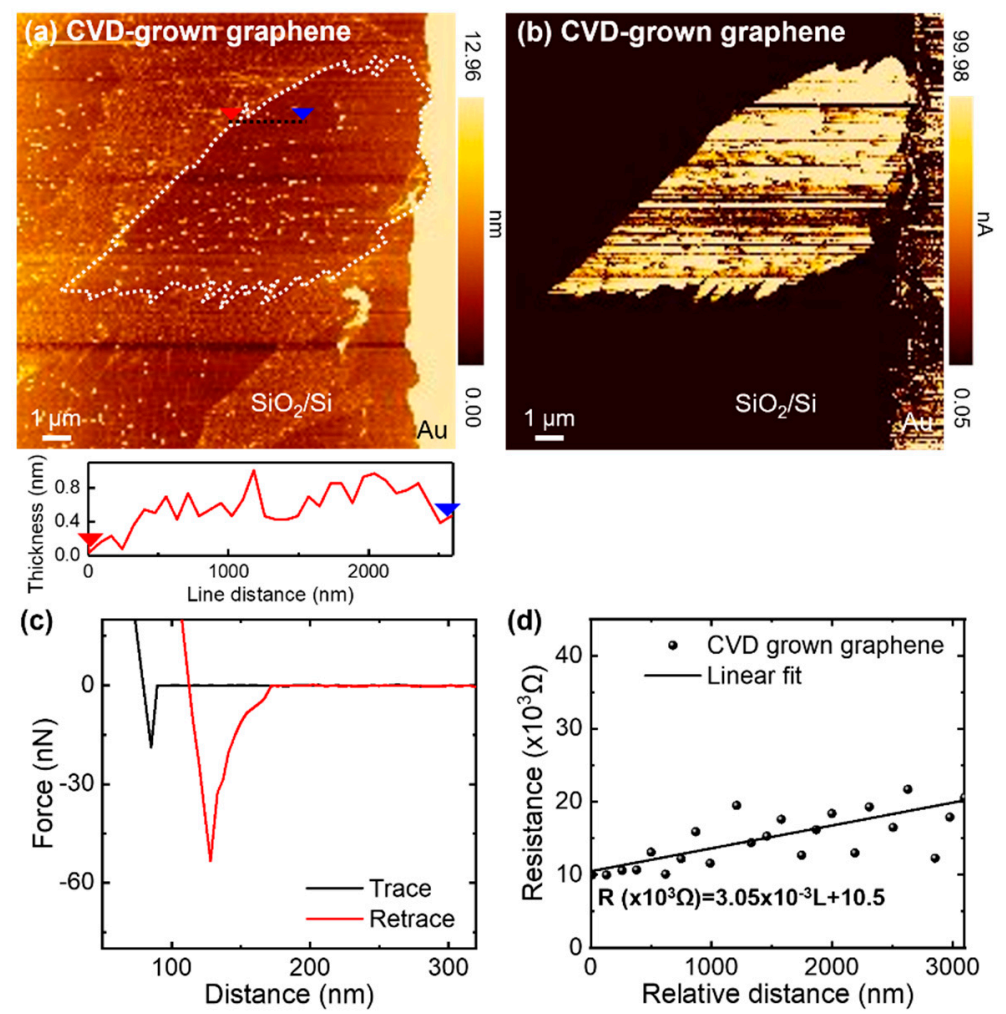

Figure 4. (a,b) AFM images for the (a) topography and (b) current distribution of the CVD-grown monolayer graphene flake on $\mathrm{SiO}_{2}$. (c) Force-distance curve. (d) Resistance profile of the graphene flake as a function of the distance from the tip to the electrode.

The GO and rGO flakes were characterized using XPS and Raman spectroscopy. The XPS C 1s core-level spectra were deconvoluted with $\mathrm{sp}^{2}$-hybridized carbon $(\mathrm{C}=\mathrm{C})$ at $284.5 \mathrm{eV}, \mathrm{sp}^{3}$-hybridized carbon (C-C) at $285.3 \mathrm{eV}, \mathrm{C}-\mathrm{O}$ at $286.3 \mathrm{eV}, \mathrm{C}=\mathrm{O}$ at $287.6 \mathrm{eV}$, and $\mathrm{O}=\mathrm{C}-\mathrm{O}$ at $288.8 \mathrm{eV}$ (Figure $5 \mathrm{a}-\mathrm{c}$ ) [38,39]. In addition, the XPS spectra of rGO flakes included $\pi-\pi^{*}$ transitions at $290.7 \mathrm{eV}$ [40-42]. Based on the XPS analysis, the GO flakes had a C/O ratio of 1.5, which is similar to that of typical GO [43]. The thermal treatment partially removed oxygen functional groups, thereby increasing the $\mathrm{C} / \mathrm{O}$ ratio to 4.6 and 5.3 for the rGO flakes annealed at 300 and $600{ }^{\circ} \mathrm{C}$, respectively. The Raman spectra of GO and rGO showed typical D and G bands at $\sim 1350$ and $\sim 1580 \mathrm{~cm}^{-1}$, respectively (Figure 5d) [44]. To obtain an accurate estimation of the intensity ratio of the D peak to the $\mathrm{G}$ peak, $\mathrm{I}_{\mathrm{D}} / \mathrm{I}_{\mathrm{G}}$, the broad $\mathrm{D}$ and $\mathrm{G}$ bands were deconvoluted into five components, as shown in Figure 6: G $\left(\sim 1580 \mathrm{~cm}^{-1}\right), \mathrm{D}\left(\sim 1350 \mathrm{~cm}^{-1}\right), \mathrm{D}^{*}\left(\sim 1150-1200 \mathrm{~cm}^{-1}\right), \mathrm{D}^{\prime \prime}(\sim 1500$ $\left.1550 \mathrm{~cm}^{-1}\right)$, and $\mathrm{D}^{\prime}\left(\sim 1620 \mathrm{~cm}^{-1}\right)$ [45-48]. Three pseudo-Voigt (for $\mathrm{D}, \mathrm{G}$, and $\mathrm{D}^{\prime}$ peaks) and two Gaussian (for $\mathrm{D}^{*}$ and $\mathrm{D}^{\prime \prime}$ peaks) functions were used to fit the Raman spectra in the range of $1000-1800 \mathrm{~cm}^{-1}$ [48]. The analysis of the Raman spectra revealed that $\mathrm{I}_{\mathrm{D}} / \mathrm{I}_{\mathrm{G}}$ decreased from $1.56 \pm 0.06$ for the GO flakes to $1.32 \pm 0.07$ and $1.08 \pm 0.06$ for the rGO flakes annealed at 300 and $600{ }^{\circ} \mathrm{C}$, respectively. The change in the characteristics of the Raman spectra indicates the removal of oxygen functional groups [49,50], which is in good agreement with the XPS analysis. 

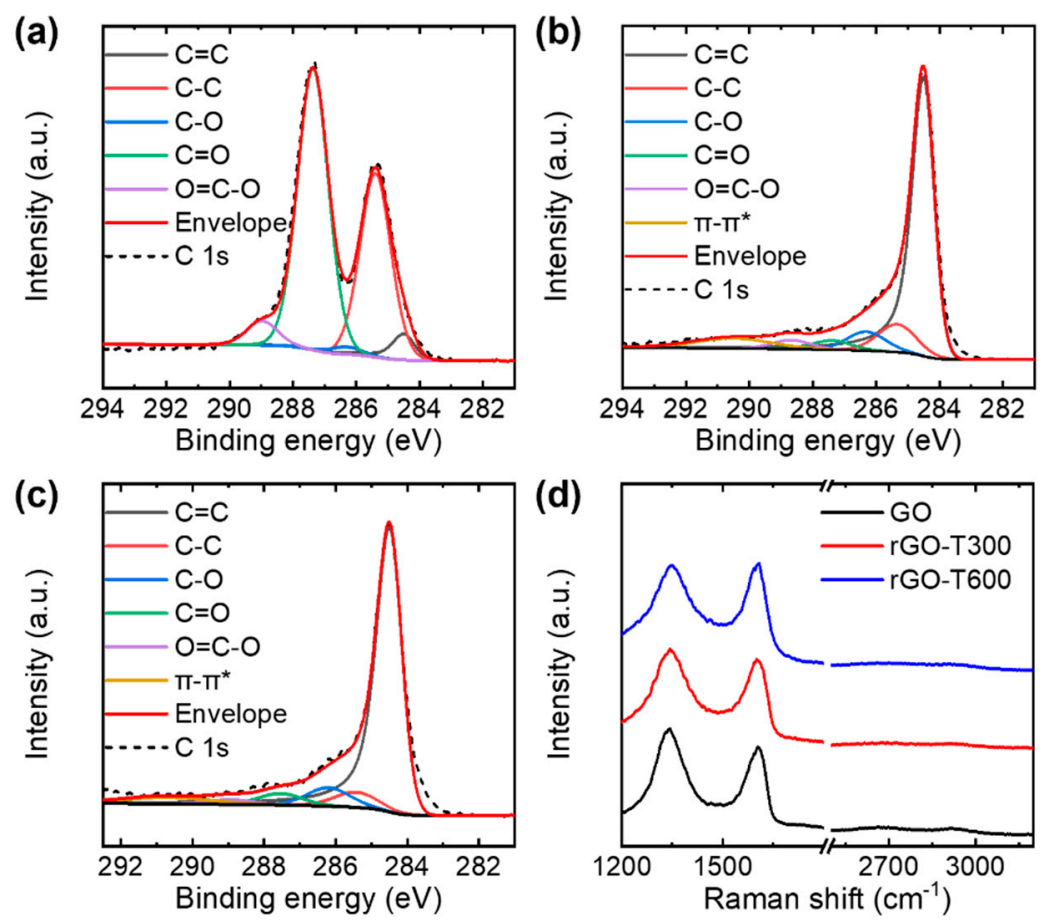

Figure 5. (a-c) XPS C 1s spectra of (a) GO and (b,c) rGO flakes. Thermal annealing was performed at (b) 300 and (c) $600{ }^{\circ} \mathrm{C}$. (d) Raman spectra of GO and rGO flakes. rGO-T300 and rGO-T600 denote rGO flakes annealed at 300 and $600{ }^{\circ} \mathrm{C}$, respectively.
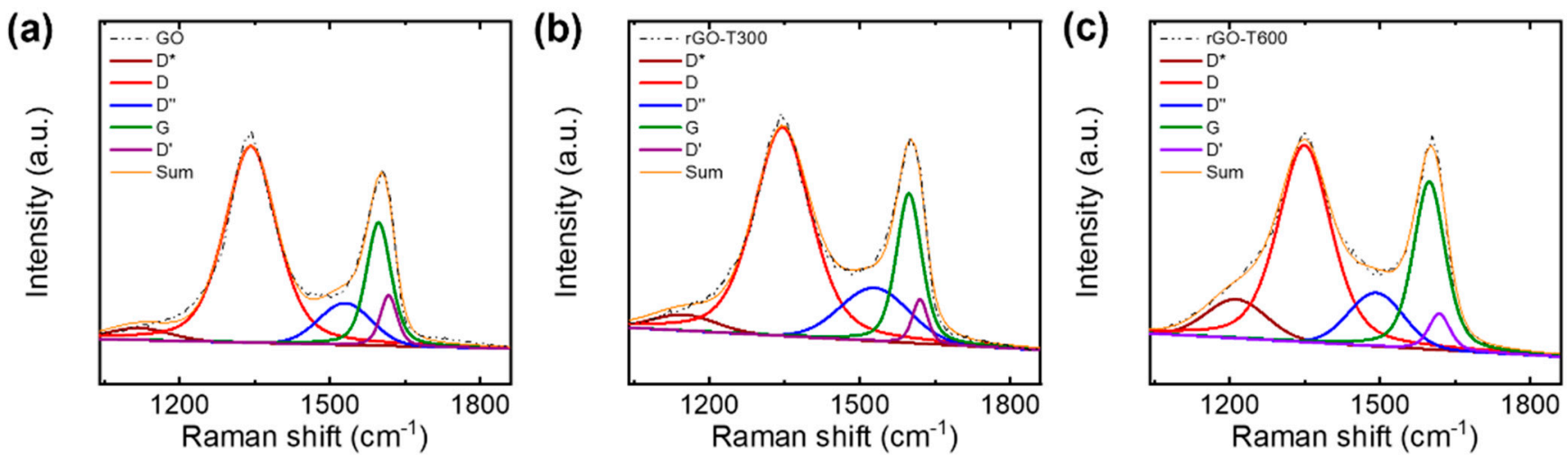

Figure 6. Deconvolution of Raman spectra of (a) GO and (b,c) rGO flakes.

Figure 7a,c shows the AFM topography of the rGO flakes synthesized by the thermal annealing of GO flakes at 300 and $600{ }^{\circ} \mathrm{C}$, respectively. The thickness of the rGO annealed at $300{ }^{\circ} \mathrm{C}$ was $\sim 1.0 \mathrm{~nm}$, whereas the rGO flake annealed at $600{ }^{\circ} \mathrm{C}$ had a thickness of $\sim 0.6 \mathrm{~nm}$, confirming the greater removal of oxygen functional groups at a higher temperature. Figure $7 \mathrm{~b}, \mathrm{~d}$ presents the corresponding current maps of the rGO flakes. The force-distance curves of the rGO flakes annealed at 300 and $600{ }^{\circ} \mathrm{C}$ provided pull-off forces of $63.0 \pm 10.4 \mathrm{nN}$ and $74.5 \pm 5.5 \mathrm{nN}$, respectively (Figure 7e). This shows that the effective contact areas between the tip and the rGO flake were $18.643 \mathrm{~nm}^{2}\left(\mathrm{~W}_{\mathrm{t}}=4.872 \mathrm{~nm}\right)$ and $20.750 \mathrm{~nm}^{2}\left(\mathrm{~W}_{\mathrm{t}}=5.140 \mathrm{~nm}\right)$ at annealing temperatures of 300 and $600{ }^{\circ} \mathrm{C}$, respectively. Therefore, using the given equation to fit the resistance-distance curves, the electrical conductivities were estimated to be $2.3 \pm 1.0$ and $14.6 \pm 5.5 \mathrm{~S} / \mathrm{m}$ for 300 and $600{ }^{\circ} \mathrm{C}$ annealing samples, respectively (Figure 7f). This indicates that a greater reduction of GO provided a higher electrical conductivity along with a higher $\mathrm{C} / \mathrm{O}$ ratio and lower $\mathrm{I}_{\mathrm{D}} / \mathrm{I}_{\mathrm{G}}$. Several previous studies have investigated the electrical conductivity of isolated graphene flakes. Monolayer rGO flakes with a $\mathrm{C} / \mathrm{O}$ ratio of $\sim 4$ synthesized by the photoreduction of GO us- 
ing ultraviolet light irradiation in vacuum exhibited an electrical conductivity of $0.20 \mathrm{~S} / \mathrm{m}$, which was directly measured by C-AFM [51]. Moreover, four-probe measurements using micropatterned electrodes deposited on $\mathrm{GO}$ flakes showed electrical conductivities ranging from 33 to $85 \mathrm{~S} / \mathrm{m}$ after a partial reduction by thermal annealing in vacuum [43]. A similar measurement method showed that monolayer rGO flakes obtained by the chemical reduction of GO via hydrazine had electrical conductivities ranging between 5 and $200 \mathrm{~S} / \mathrm{m}$ [52]. Considering that GO flakes were partially reduced by thermal annealing at relatively low temperatures, the electrical conductivities reported in previous studies are comparable to those measured by C-AFM in this study.
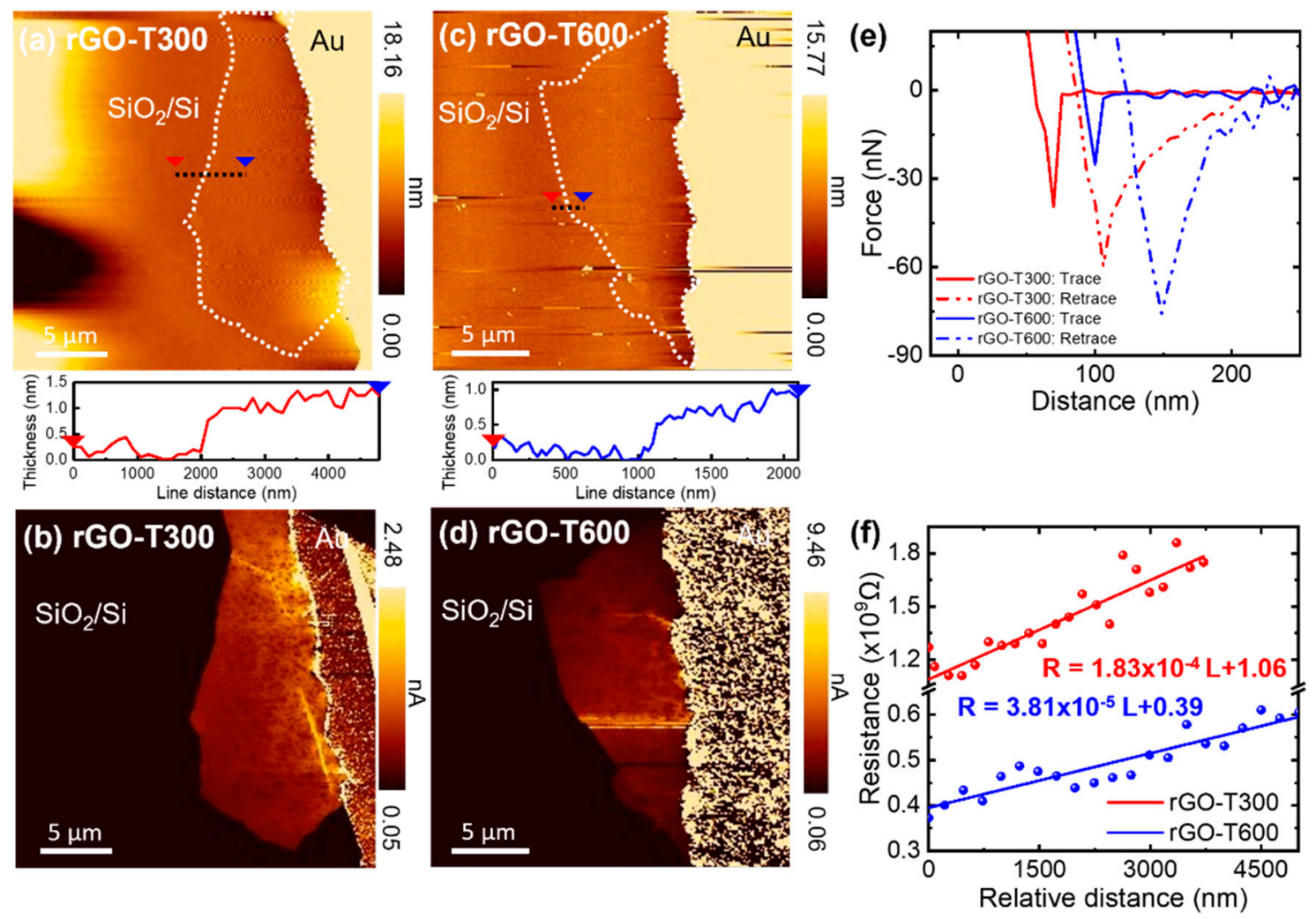

Figure 7. (a,b) AFM images for the (a) topography and (b) current distribution of the rGO flake annealed at $300{ }^{\circ} \mathrm{C}$. (c,d) AFM images for the (c) topography and (d) current distribution of the rGO flake annealed at $600{ }^{\circ} \mathrm{C}$. (e) Force-distance curves. (f) Resistance profiles of the rGO flakes as a function of the distance from the tip to the electrode.

\section{Conclusions}

The electrical conductivities of isolated graphene flakes were investigated using CAFM and an analytical analysis. Monolayer graphene flakes obtained by CVD on copper foil and the thermal reduction of GO were characterized using C-AFM. High-quality CVDgrown monolayer graphene flakes transferred onto $\mathrm{SiO}_{2} / \mathrm{Si}$ exhibited a high electrical conductivity comparable to that measured by the van der Pauw method. In addition, GO flakes placed on $\mathrm{SiO}_{2} / \mathrm{Si}$ were thermally reduced at two different temperatures. Annealing the rGO flakes at higher temperatures resulted in a higher electrical conductivity, which was confirmed by an increase in the $\mathrm{C} / \mathrm{O}$ ratio and a decrease in $\mathrm{I}_{\mathrm{D}} / \mathrm{I}_{\mathrm{G}}$. This study demonstrates that the C-AFM method is capable of estimating the local electrical conductivity of individual graphene flakes. In addition, this study provides a better understanding of graphene materials synthesized using the two major scalable production methods.

Author Contributions: Conceptualization, J.W.S.; Methodology, S.L. and J.W.S.; Formal analysis, S.L., H.P., and J.W.S.; Investigation, S.L. and H.P.; Resources, G.Y. and C.L.; Writing-Original Draft Preparation, S.L. and J.W.S.; Writing—Review \& Editing, G.Y., C.L., and J.W.S.; Supervision, J.W.S.; 
Project Administration, J.W.S.; Funding Acquisition, J.W.S. All authors have read and agreed to the published version of the manuscript.

Funding: This work was supported by the Nano-Material Technology Development Program through the National Research Foundation of Korea (NRF) grant funded by the Ministry of Science and ICT (No. 2016M3A7B4900121). It was also supported by the Commercialization Promotion Agency for R\&D Outcomes (COMPA) funded by the Ministry of Science and ICT (2021-RMC-P02-3, Optimization of the quality evaluation for size-controlled graphene oxide). In addition, the work was supported by the Korea Institute of Industrial Technology (kitech JA-21-0001) and the Gyeonggi-Do Technology Development Program (kitech IZ-21-0001) as "Development of smart textronic products based on electronic fibers and textiles".

Institutional Review Board Statement: Not applicable.

Informed Consent Statement: Not applicable.

Data Availability Statement: Not applicable.

Conflicts of Interest: The authors declare no conflict of interest.

\section{References}

1. Novoselov, K.S.; Geim, A.K.; Morozov, S.V.; Jiang, D.; Zhang, Y.; Dubonos, S.V.; Grigorieva, I.V.; Firsov, A.A. Electric Field Effect in Atomically Thin Carbon Films. Science 2004, 306, 666-669. [CrossRef]

2. Zhang, Y.; Tan, Y.-W.; Stormer, H.L.; Kim, P. Experimental observation of the quantum Hall effect and Berry's phase in graphene. Nature 2005, 438, 201-204. [CrossRef] [PubMed]

3. Novoselov, K.S.; Geim, A.K.; Morozov, S.V.; Jiang, D.; Katsnelson, M.I.; Grigorieva, I.V.; Dubonos, S.V.; Firsov, A.A. Twodimensional gas of massless Dirac fermions in graphene. Nature 2005, 438, 197-200. [CrossRef]

4. Bolotin, K.I.; Sikes, K.J.; Jiang, Z.; Klima, M.; Fudenberg, G.; Hone, J.; Kim, P.; Stormer, H.L. Ultrahigh electron mobility in suspended graphene. Solid State Commun. 2008, 146, 351-355. [CrossRef]

5. Lee, C.; Wei, X.; Kysar, J.W.; Hone, J. Measurement of the elastic properties and intrinsic strength of monolayer graphene. Science 2008, 321, 385-388. [CrossRef]

6. Balandin, A.A.; Ghosh, S.; Bao, W.; Calizo, I.; Teweldebrhan, D.; Miao, F.; Lau, C.N. Superior Thermal Conductivity of Single-Layer Graphene. Nano Lett. 2008, 8, 902-907. [CrossRef]

7. Nair, R.R.; Blake, P.; Grigorenko, A.N.; Novoselov, K.S.; Booth, T.J.; Stauber, T.; Peres, N.M.R.; Geim, A.K. Fine Structure Constant Defines Visual Transparency of Graphene. Science 2008, 320, 1308. [CrossRef]

8. Li, X.; Cai, W.; An, J.; Kim, S.; Nah, J.; Yang, D.; Piner, R.; Velamakanni, A.; Jung, I.; Tutuc, E. Large-area synthesis of high-quality and uniform graphene films on copper foils. Science 2009, 324, 1312-1314. [CrossRef]

9. Stankovich, S.; Dikin, D.A.; Piner, R.D.; Kohlhaas, K.A.; Kleinhammes, A.; Jia, Y.; Wu, Y.; Nguyen, S.T.; Ruoff, R.S. Synthesis of graphene-based nanosheets via chemical reduction of exfoliated graphite oxide. Carbon 2007, 45, 1558-1565. [CrossRef]

10. Yu, Q.; Jauregui, L.A.; Wu, W.; Colby, R.; Tian, J.; Su, Z.; Cao, H.; Liu, Z.; Pandey, D.; Wei, D.; et al. Control and characterization of individual grains and grain boundaries in graphene grown by chemical vapour deposition. Nat. Mater. 2011, 10, 443-449. [CrossRef] [PubMed]

11. Zhu, Y.; Murali, S.; Cai, W.; Li, X.; Suk, J.W.; Potts, J.R.; Ruoff, R.S. Graphene and Graphene Oxide: Synthesis, Properties, and Applications. Adv. Mater. 2010, 22, 3906-3924. [CrossRef]

12. Jung, I.; Dikin, D.A.; Piner, R.D.; Ruoff, R.S. Tunable Electrical Conductivity of Individual Graphene Oxide Sheets Reduced at "Low" Temperatures. Nano Lett. 2008, 8, 4283-4287. [CrossRef] [PubMed]

13. Gómez-Navarro, C.; Meyer, J.C.; Sundaram, R.S.; Chuvilin, A.; Kurasch, S.; Burghard, M.; Kern, K.; Kaiser, U. Atomic Structure of Reduced Graphene Oxide. Nano Lett. 2010, 10, 1144-1148. [CrossRef] [PubMed]

14. Dikin, D.A.; Stankovich, S.; Zimney, E.J.; Piner, R.D.; Dommett, G.H.B.; Evmenenko, G.; Nguyen, S.T.; Ruoff, R.S. Preparation and characterization of graphene oxide paper. Nature 2007, 448, 457-460. [CrossRef] [PubMed]

15. Park, H.; Lim, S.; Nguyen, D.D.; Suk, J.W. Electrical Measurements of Thermally Reduced Graphene Oxide Powders under Pressure. Nanomaterials 2019, 9, 1387. [CrossRef]

16. Stankovich, S.; Dikin, D.A.; Dommett, G.H.B.; Kohlhaas, K.M.; Zimney, E.J.; Stach, E.A.; Piner, R.D.; Nguyen, S.T.; Ruoff, R.S. Graphene-based composite materials. Nature 2006, 442, 282-286. [CrossRef]

17. Mativetsky, J.M.; Treossi, E.; Orgiu, E.; Melucci, M.; Veronese, G.P.; Samorì, P.; Palermo, V. Local Current Mapping and Patterning of Reduced Graphene Oxide. J. Am. Chem. Soc. 2010, 132, 14130-14136. [CrossRef]

18. Li, J.; Wu, J.; Huang, Z.; Qi, X.; Zhong, J. Local conductivity of graphene oxide study by conductive atomic force microscope. J. Appl. Phys. 2019, 126, 215701. [CrossRef]

19. Kubota, W.; Utsunomiya, T.; Ichii, T.; Sugimura, H. Local current mapping of electrochemically-exfoliated graphene oxide by conductive AFM. Jpn. J. Appl. Phys. 2020, 59, SN1001. [CrossRef] 
20. Li, X.; Zhu, Y.; Cai, W.; Borysiak, M.; Han, B.; Chen, D.; Piner, R.D.; Colombo, L.; Ruoff, R.S. Transfer of large-area graphene films for high-performance transparent conductive electrodes. Nano Lett. 2009, 9, 4359-4363. [CrossRef]

21. Suk, J.W.; Kitt, A.; Magnuson, C.W.; Hao, Y.; Ahmed, S.; An, J.; Swan, A.K.; Goldberg, B.B.; Ruoff, R.S. Transfer of CVD-Grown Monolayer Graphene onto Arbitrary Substrates. ACS Nano 2011, 5, 6916-6924. [CrossRef] [PubMed]

22. Tu, Y.; Utsunomiya, T.; Ichii, T.; Sugimura, H. Enhancing the electrical conductivity of vacuum-ultraviolet-reduced graphene oxide by multilayered stacking. J. Vac. Sci. Technol. B 2017, 35, 03D110. [CrossRef]

23. Venugopal, A.; Colombo, L.; Vogel, E. Contact resistance in few and multilayer graphene devices. Appl. Phys. Lett. 2010, 96, 013512. [CrossRef]

24. Suriano, R.; Credi, C.; Levi, M.; Turri, S. AFM nanoscale indentation in air of polymeric and hybrid materials with highly different stiffness. Appl. Surf. Sci. 2014, 311, 558-566. [CrossRef]

25. Wang, M.; Liechti, K.M.; White, J.M.; Winter, R.M. Nanoindentation of polymeric thin films with an interfacial force microscope. J. Mech. Phys. Solids 2004, 52, 2329-2354. [CrossRef]

26. Derjaguin, B.V.; Muller, V.M.; Toporov, Y.P. Effect of contact deformations on the adhesion of particles. J. Colloid Interface Sci. 1975, 53, 314-326. [CrossRef]

27. Suk, J.W.; Na, S.R.; Stromberg, R.J.; Stauffer, D.; Lee, J.; Ruoff, R.S.; Liechti, K.M. Probing the adhesion interactions of graphene on silicon oxide by nanoindentation. Carbon 2016, 103, 63-72. [CrossRef]

28. Frammelsberger, W.; Benstetter, G.; Kiely, J.; Stamp, R. C-AFM-based thickness determination of thin and ultra-thin SiO2 films by use of different conductive-coated probe tips. Appl. Surf. Sci. 2007, 253, 3615-3626. [CrossRef]

29. Gómez-Navarro, C.; Burghard, M.; Kern, K. Elastic Properties of Chemically Derived Single Graphene Sheets. Nano Lett. 2008, 8, 2045-2049. [CrossRef]

30. Suk, J.W.; Murali, S.; An, J.; Ruoff, R.S. Mechanical measurements of ultra-thin amorphous carbon membranes using scanning atomic force microscopy. Carbon 2012, 50, 2220-2225. [CrossRef]

31. Doniach, S.; Sunjic, M. Many-electron singularity in X-ray photoemission and X-ray line spectra from metals. J. Phys. C: Solid State Phys. 1970, 3, 285-291. [CrossRef]

32. Díaz, J.; Paolicelli, G.; Ferrer, S.; Comin, F. Separation of the $\mathrm{sp}^{3}$ and $\mathrm{sp}^{2}$ components in the C1s photoemission spectra of amorphous carbon films. Phys. Rev. B 1996, 54, 8064-8069. [CrossRef] [PubMed]

33. Li, X.; Magnuson, C.W.; Venugopal, A.; An, J.; Suk, J.W.; Han, B.; Borysiak, M.; Cai, W.; Velamakanni, A.; Zhu, Y.; et al. Graphene Films with Large Domain Size by a Two-Step Chemical Vapor Deposition Process. Nano Lett. 2010, 10, 4328-4334. [CrossRef] [PubMed]

34. Ishigami, M.; Chen, J.H.; Cullen, W.G.; Fuhrer, M.S.; Williams, E.D. Atomic Structure of Graphene on $\mathrm{SiO}_{2}$. Nano Lett. 2007, 7, 1643-1648. [CrossRef]

35. Lindvall, N.; Kalabukhov, A.; Yurgens, A. Cleaning graphene using atomic force microscope. J. Appl. Phys. 2012, 111, 064904. [CrossRef]

36. Choi, W.; Shehzad, M.A.; Park, S.; Seo, Y. Influence of removing PMMA residues on surface of CVD graphene using a contact-mode atomic force microscope. RSC Adv. 2017, 7, 6943-6949. [CrossRef]

37. Kholmanov, I.N.; Magnuson, C.W.; Aliev, A.E.; Li, H.; Zhang, B.; Suk, J.W.; Zhang, L.L.; Peng, E.; Mousavi, S.H.; Khanikaev, A.B. Improved electrical conductivity of graphene films integrated with metal nanowires. Nano Lett. 2012, 12, 5679-5683. [CrossRef]

38. Yang, D.; Velamakanni, A.; Bozoklu, G.; Park, S.; Stoller, M.; Piner, R.D.; Stankovich, S.; Jung, I.; Field, D.A.; Ventrice, C.A.; et al. Chemical analysis of graphene oxide films after heat and chemical treatments by X-ray photoelectron and Micro-Raman spectroscopy. Carbon 2009, 47, 145-152. [CrossRef]

39. Lim, T.; Ho, B.T.; Suk, J.W. High-performance and thermostable wire supercapacitors using mesoporous activated graphene deposited on continuous multilayer graphene. J. Mater. Chem. A 2021, 9, 4800-4809. [CrossRef]

40. Ranjan, P.; Agrawal, S.; Sinha, A.; Rao, T.R.; Balakrishnan, J.; Thakur, A.D. A low-cost non-explosive synthesis of graphene oxide for scalable applications. Sci. Rep. 2018, 8, 1-13.

41. Rogala, M.; Dabrowski, P.; Kowalczyk, P.; Wlasny, I.; Kozlowski, W.; Busiakiewicz, A.; Karaduman, I.; Lipinska, L.; Baranowski, J.; Klusek, Z. The observer effect in graphene oxide-How the standard measurements affect the chemical and electronic structure. Carbon 2016, 103, 235-241. [CrossRef]

42. Chang, H.; Sun, Z.; Saito, M.; Yuan, Q.; Zhang, H.; Li, J.; Wang, Z.; Fujita, T.; Ding, F.; Zheng, Z. Regulating infrared photoresponses in reduced graphene oxide phototransistors by defect and atomic structure control. ACS Nano 2013, 7, 6310-6320. [CrossRef]

43. Jung, I.; Dikin, D.; Park, S.; Cai, W.; Mielke, S.L.; Ruoff, R.S. Effect of water vapor on electrical properties of individual reduced graphene oxide sheets. J. Phys. Chem. C 2008, 112, 20264-20268. [CrossRef]

44. Suk, J.W.; Piner, R.D.; An, J.; Ruoff, R.S. Mechanical properties of monolayer graphene oxide. ACS Nano 2010, 4, 6557-6564. [CrossRef]

45. Sadezky, A.; Muckenhuber, H.; Grothe, H.; Niessner, R.; Pöschl, U. Raman microspectroscopy of soot and related carbonaceous materials: Spectral analysis and structural information. Carbon 2005, 43, 1731-1742. [CrossRef]

46. King, A.A.K.; Davies, B.R.; Noorbehesht, N.; Newman, P.; Church, T.L.; Harris, A.T.; Razal, J.M.; Minett, A.I. A New Raman Metric for the Characterisation of Graphene oxide and its Derivatives. Sci. Rep. 2016, 6, 19491. [CrossRef]

47. Lee, A.Y.; Yang, K.; Anh, N.D.; Park, C.; Lee, S.M.; Lee, T.G.; Jeong, M.S. Raman study of D* band in graphene oxide and its correlation with reduction. Appl. Surf. Sci. 2021, 536, 147990. [CrossRef] 
48. Claramunt, S.; Varea, A.; López-Díaz, D.; Velázquez, M.M.; Cornet, A.; Cirera, A. The Importance of Interbands on the Interpretation of the Raman Spectrum of Graphene Oxide. J. Phys. Chem. C 2015, 119, 10123-10129. [CrossRef]

49. Noh, S.H.; Eom, W.; Lee, W.J.; Park, H.; Ambade, S.B.; Kim, S.O.; Han, T.H. Joule heating-induced sp2-restoration in graphene fibers. Carbon 2019, 142, 230-237. [CrossRef]

50. Sreeja, V.G.; Vinitha, G.; Reshmi, R.; Anila, E.I.; Jayaraj, M.K. Effect of reduction time on third order optical nonlinearity of reduced graphene oxide. Opt. Mater. 2017, 66, 460-468. [CrossRef]

51. Tu, Y.; Ichii, T.; Utsunomiya, T.; Sugimura, H. Vacuum-ultraviolet photoreduction of graphene oxide: Electrical conductivity of entirely reduced single sheets and reduced micro line patterns. Appl. Phys. Lett. 2015, 106, 133105. [CrossRef]

52. Gómez-Navarro, C.; Weitz, R.T.; Bittner, A.M.; Scolari, M.; Mews, A.; Burghard, M.; Kern, K. Electronic transport properties of individual chemically reduced graphene oxide sheets. Nano Lett. 2007, 7, 3499-3503. [CrossRef] [PubMed] 